\title{
August 26 Highlights
}

\section{Efficacy of donepezil in vascular dementia}

Wilkinson et al. studied the effects of the acetylcholinesterase inhibitor donepezil in 616 patients with vascular dementia. At 24 weeks, patients treated with donepezil $5 \mathrm{mg} /$ day or $10 \mathrm{mg} /$ day demonstrated significant benefits vs placebo in both cognition and global function.

see page 479

\section{Commentary by Martin Farlow, MD}

The prevalence of vascular dementia (VaD) ranks only behind that of Alzheimer's disease (AD), but no therapies until now have been established to delay disease progression or improve cognitive symptoms. The pattern of progression differs from $\mathrm{AD}$, in that cognitive decline in $\mathrm{VaD}$ as defined by National Institute of Neurological Disorders and StrokeAssociation Internationale pour la Recherche en l'Enseignement en Neurosciences criteria typically occurs in sharp drops that may be associated with strokes rather than the steady decline more typically seen in $\mathrm{AD}$. In a clinical trial setting, where patients with VaD may more regularly receive therapy for vascular risk factors, there may be no decline in cognitive functioning. In the doubleblind, placebo-controlled trial of two doses of donepezil reported in this issue of Neurology by Wilkinson et al., exactly this result was seen, as illustrated in the figure, with the placebo group actually slightly improved versus baseline on $\mathrm{AD}$ Assessment Scale-Cognitive Subscale scores. This absence of progression creates a higher hurdle for demonstrating beneficial clinical effects that was nonetheless surmounted by both the donepezil $5 \mathrm{mg} /$ day and donepezil $10 \mathrm{mg} /$ day groups with significant cognitive improvements versus placebo in

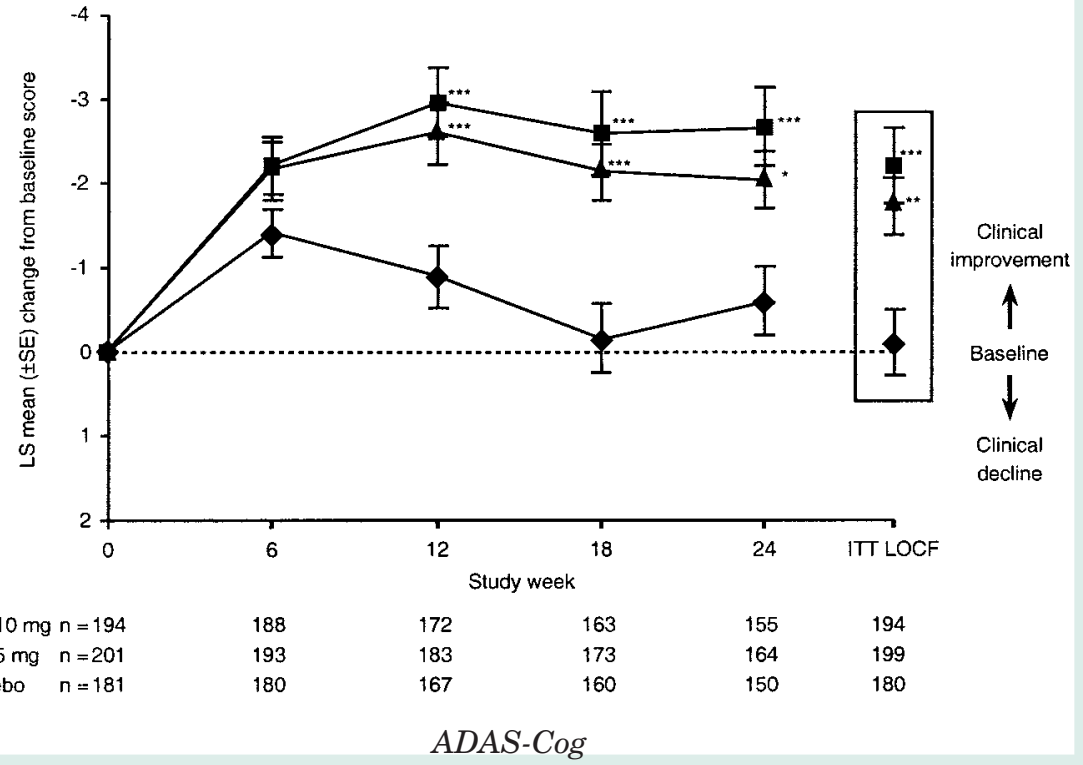

each, a result consistent with other recent vascular dementia therapeutic trials. ${ }^{1,2}$

The magnitude of improvements seen in this study was very similar for both the donepezil 5 $\mathrm{mg} / \mathrm{day}$ and donepezil $10 \mathrm{mg} /$ day groups, with somewhat better performance on the CIBIC-plus for the $5 \mathrm{mg} /$ day group, whereas in the $10 \mathrm{mg} /$ day group versus placebo, a significantly greater percentage of patients experienced diarrhea, nausea, abnormal dreams, leg cramps, and rhinitis. The results suggest a narrower therapeutic window for donepezil with lower optimal dosage, balancing efficacy and drug adverse effects, in $\mathrm{VaD}$ than for $\mathrm{AD}$. None- theless, this study and other recent reports provide a strong evidence base supporting the general use of donepezil, and possibly in the future other cholinesterase inhibitors, for treating cognitive symptoms in $\mathrm{VaD}$.

\section{References}

1. Kittner B, De Deyn PP, Erkinjuntti $T$. Investigating the natural course and treatment of vascular dementia and Alzheimer's disease. Parallel study populations in two randomized placebo-controlled trials. Ann NY Acad Sci 2000;903:535-541.

2. Orgogozo JM, Rigaud AS, Stoffler A, Mobius HJ, Forette F. Efficacy and safety of memantine in patients with mild to moderate vascular dementia: a randomized, placebo controlled trial (MMM 300). Stroke 2002; 33:1834-1839. 


\section{Long-term outcome after epilepsy surgery}

Yoon et al. studied the long-term course of 175 patients who were initially seizure-free after resective epilepsy surgery. They found that the proportion remaining seizure-free declined to $56 \%$ over 10 years, but half of those who relapsed had at most one seizure/year. Patients with longer preoperative illness, longer duration of preoperative epilepsy, older age at surgery, and normal pathology had worse outcomes.

see page $\mathbf{4 4 5}$

Physicians will do well to refer all patients with partial epilepsy who fail two antiseizure drugs for consideration of surgery: epilepsy surgery centers should consider early intervention surgical trials a priority, and be willing to modify clinical practice based upon the results.
The accompanying editorial by Trevathan and Gilliam points out that this study not only documented excellent seizure-free rates, it also documented years of potentially surgically treatable epilepsy during childhood, adolescence, and young adulthood before referral for surgical evaluation. However, so few patients had surgery within the first 10 years of their epilepsy that we do not know if earlier intervention would have offered these patients improved odds for seizure freedom. A multicenter clinical trial is being initiated to address this question. Clinical trials to address the potential benefit of early surgical intervention are being planned and initiated.

see page 432

\section{Brain volume change predicts AD pathology}

Silbert et al. studied MRI volume change during life in 39 subjects across a range of cognitive abilities in relation to postmortem $\mathrm{AD}$ pathology. The best predictor of cortical neurofibrillary tangles and senile plaques was the rate of ventricular volume increase.

see page 487

\section{Motor cortex disinhibition in complex regional pain syndrome}

Schwenkreis et al. studied motor cortex excitability in patients with complex regional pain syndrome using paired pulse transcranial magnetic stimulation. They found a bilaterally reduced intracortical inhibition, giving additional evidence for a widespread involvement of the CNS as a cause or consequence of the disease.

see page 515

\section{Clinical trial of topiramate in ALS: Significant adverse effects}

Cudkowicz et al. and the Northeast ALS Consortium conducted a double-blind, placebo-controlled, multicenter clinical trial of topiramate in 296 patients with ALS. At the maximum tolerated dose, up to $800 \mathrm{mg} /$ day, topiramate did not have a beneficial effect and was associated with an increased risk for several adverse events.

see page 456

\section{Clinical trials in ALS: Is there a better way?}

The accompanying editorial by Kaufmann and Lomen-Hoerth considers this negative trial, asking whether a different trial design could have avoided yet another large negative trial, and could have subjected fewer patients to the adverse effects of topiramate. The only successful treatment for ALS, riluzole, showed predictive benefit in an animal model. However, other agents effective in a model have not helped in $A L S$. They point out that the large number of putative treatments requiring study in ALS dictates that we have better outcome measures that allow more rapid endpoints and conclusions than does the current gold standard-patient survival.

see page 434

\section{Oxidative stress and neurodegeneration: Distinguishing AD from FTD}

Yao et al. quantified isoprostane $\mathrm{F}_{2 \alpha}-\mathrm{VI}$, a specific marker of lipid peroxidation, in brain tissues from patients with $\mathrm{AD}$, patients with frontotemporal dementia (FTD), and control subjects. They found that compared with controls, brain lipid peroxidation marker levels were increased in patients with $\mathrm{AD}$ but not in patients with FTD.

see page 475

The accompanying editorial by Irizarry and Hyman notes the evidence that the $A D$ brain sustains oxidative damage that may contribute to extracellular amyloid plaques and intracelIular neurofibrillary tangles ultimately leading to neuronal death. Isoprostanes, which are prostaglandin-like compounds, are produced in cell membrane phospholipids and their release from membrane lipid bilayers by phospholipases reflects lipid peroxidation state. $F_{2 \alpha}$-isoprostane measurement has promise as a marker for the effectiveness of antioxidant therapy in clinical trials or prevention studies in $A D$. 


\section{Cobratoxin for treatment of adrenomyeloneuropathy?}

Mundy et al. conducted a double-blinded placebo-controlled study of oral modified cobratoxin in ambulatory patients with adrenomyeloneuropathy. Although treatment appeared safe, there were no significant benefits.

see page 526

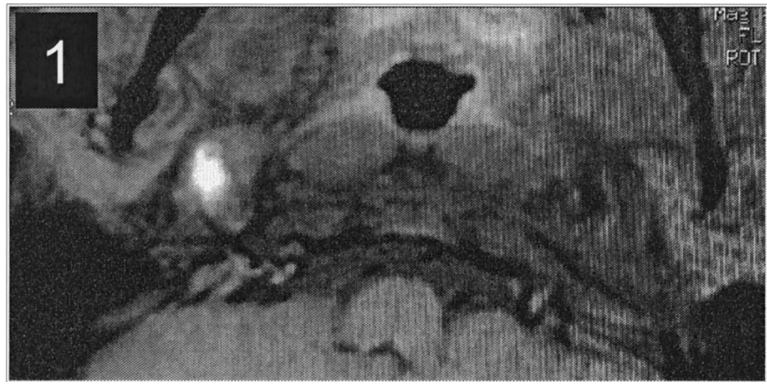

Dissection of the stenotic right carotid vs normal

\section{Sumatriptan is effective for headache in MELAS}

Iizuka et al. reported two patients with MELAS who had complete resolution of headache within 15 minutes following subcutaneous injection of sumatriptan.

see page 577

\section{Asymptomatic recurrences of cervical artery dissection}

Touzé et al. observed three patients with early asymptomatic recurrence of cervical artery dissection, suggesting that early recurrences may be underestimated. However, the prognosis of these patients remained good.

see page 572 


\section{Neurology}

\section{August 26 Highlights}

Neurology 2003;61;429

DOI 10.1212/WNL.61.4.429

This information is current as of August 25, 2003

\section{Updated Information \&} Services

References

Permissions \& Licensing

Reprints including high resolution figures, can be found at: http://n.neurology.org/content/61/4/429.full

This article cites 2 articles, 1 of which you can access for free at: http://n.neurology.org/content/61/4/429.full\#ref-list-1

Information about reproducing this article in parts (figures,tables) or in its entirety can be found online at:

http://www.neurology.org/about/about_the_journal\#permissions

Information about ordering reprints can be found online:

http://n.neurology.org/subscribers/advertise

Neurology ${ }^{\circledR}$ is the official journal of the American Academy of Neurology. Published continuously since 1951, it is now a weekly with 48 issues per year. Copyright . All rights reserved. Print ISSN: 0028-3878. Online ISSN: 1526-632X.

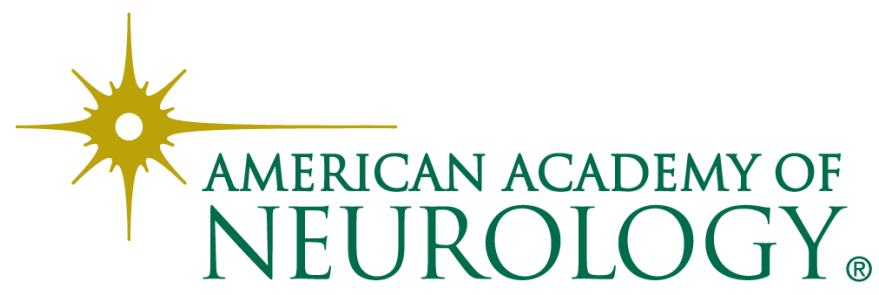

